\title{
Evaluation of Biological Effects of Nanosystems of Directed Transport in Experiments in Vivo and Their Application Possibilities in Anti-Tumor Therapy
}

\author{
Vasyl F. Chekhun, Lesia A. Naleskina, Liudmila Z. Polishchuk, Igor M. Todor, \\ Dmytro V. Demash, Natalia Yu. Lukianova \\ Department of Mechanisms of Anti-Tumor Therapy, RE Kavetsky Institute of Experimental Pathology, \\ Oncology and Radiobiology of National Academy of Sciences of Ukraine, Kyiv, Ukraine \\ Email: chekhun@owa.nas.gov.ua
}

Received January 3, 2013; revised February 4, 2013; accepted February 12, 2013

Copyright (C) 2013 Vasyl F. Chekhun et al. This is an open access article distributed under the Creative Commons Attribution License, which permits unrestricted use, distribution, and reproduction in any medium, provided the original work is properly cited.

\begin{abstract}
The aim of the investigations was to evaluate benefits of the directed transport system - a nanocomposite, based on cisplatin and magnetite combined with local action of constant magnetic field on the tumor, in experiments in vivo in animals with transplantable Guerin carcinoma. Animals were divided into 5 groups according to the type of agent. We showed that nanocomposite in combination with static magnetic field exercises more prominent anti-tumor activity than cisplatin alone. It should be noted that regardless of the therapeutic agent, in Guerin carcinoma we observed cytotoxic effects of the same profile type. However, the degree of these changes' manifestation depended on the type of applied factor. The most prominent manifestations of pathomorphosis in tumor tissue were observed under combined action of nanocompositte and static magnetic field. Comparative analysis of the results of using as anti-tumor drugs cisplatin; cisplatin in combination with tumor exposure to static magnetic field; nanocomposite, and combination of nanocomposite with static magnetic field, showed that the most pronounced cytotoxic effect in tumors was achieved with nanosystem of targeted transport. Comparison analysis of nanocomposite accumulation in tumors of animals received only nanocomposite with the results of its accumulation after magnetic field local tumor exposure showed that the static magnetic field results in greater NC inflow to the tumor. Nanocomposite administration resulted in changes of both total lipids and phospholipids compositions in tumor tissue. At the same time, phospholipids composition in the liver of animals treated with nanocomposite did not change in fact. The administration of nanocomposite did not affect the blood total indexes, but increased serum creatinine level. Lack of significant damaging effect of nanocomposite on total and biochemical blood indexes, lipid composition of hepatocytes indicates its low toxicity and suggests the possibility of its use as a vector in nanosystems for anti-tumor drugs delivery.
\end{abstract}

Keywords: Oncology; Nanocomposite; Static Magnetic Field; Cisplatin; Anti-Tumor Activity; Guerin Carcinoma

\section{Introduction}

In the past two decades nanotechnologies made great contribution into biological and medical sciences all over the world [1-3]. This includes experimental and clinical oncology because cancer morbidity and mortality are still high and do not reduce [4].

In oncological science remarkable progress had been made during past years towards molecular markers of cancer which could be potential targets for anticancer treatment. It is known that the main approach for cancer treatment is chemotherapy, although it has its limitations due to toxicity and tumor drug resistance $[5,6]$.
During recent years new scopes appeared to develop novel agents or site-specific delivery systems to transfer these chemotherapeutic agents which can nullify the major obstacles of chemotherapy [7,8]. Nanotechnology is an interdisciplinary science which allows to study interaction of nanoparticles (NPs) with biomolecules on the cell surface as well as inside the cell. This is also actual problem in experimental and clinical oncology. Currently used NPs in cancer therapeutics include liposomes, lipids, dendrimers and metallic NPs $[9,10]$. Tumor targeted NPs can enter tumor cells from extracellular space $[11,12]$.

Use of these metallic NPs is based on hypothesis of site-specific delivery to tumor with magnetically respon- 
sive NPs vector. NPs can be modified in numerous ways to prolong circulation, enhance drug localization, increase drug efficacy, and decrease changes of multidrug resistance by means of nanotechnology. Such ferromagnetics can be used as to cause hyperthermia as to deliver drugs to tumor cells. Results of studies of magnetic drug vectors can provide a new therapeutic strategy for cancer patients [13].

"Cisplatin-magnetic fluid" nanocomposite consists of $10-12 \mathrm{~nm} \mathrm{Fe}_{3} \mathrm{O}_{4}$ nanoparticles $\left(\mathrm{Fe}_{3} \mathrm{O}_{4}\right.$ concentration is 3 $\mathrm{mg} / \mathrm{ml})$ stabilized with sodium oleate which are conjugated with cisplatin (cisplatin concentration is $350 \mathrm{mkg}$ / ml) [14].

In our previous studies we sugested that [15] nanocomposite (NC) has higher cytotoxic activity compared to cisplatin both in sensitive and resistant MCF-7 cells. It should be mentioned that sensitive and especially resistant MCF-7 cells under NC impact showed higher number of apoptotic cells compared to these cells incubated with CP.

The aim of the investigations was to evaluate benefits of the directed transport system - a nanocomposite, based on cisplatin and magnetite combined with local action of constant magnetic field on the tumor, in experiments in vivo in animals with transplantable Guerin carcinoma.

\section{Materials and Methods}

\subsection{Animals}

The study was performed on 50 male Wistar rats with body weight of 145 - $155 \mathrm{~g}$ according to the international guidelines of work with laboratory animals approved by Bioethics Committee of R.E. Kavetsky IEPOR NASU (Kyiv, Ukraine). Guerin carcinoma was transplanted subcutaneously into interscapular region by injection of 0.5 $\mathrm{ml}$ of tumor cell suspension $(2 \times 106$ cells per animal $)$. Application of cisplatin and NC started from the $9^{\text {th }}$ day after tumor transplantation. Animals were housed into 5 groups according to the type of agent (Table 1).
2 days after the last injection of cisP or NC euthanasia of experimental rats under anaesthesia ("Ketamine-plus", $1.0 \mathrm{mkl} / \mathrm{kg}$, i.m.) was performed. On the electronic balance the tumor mass (in grams) was determined.

\subsection{Histopathological and Ultrastructural Studies}

The rats' body weight was recorded before NP administration and on $10^{\text {th }}, 13^{\text {th }}, 15^{\text {th }}, 20^{\text {th }}$ day after tumor transplantation, and also on the day of sacrifice in ketamine narcosis. After macroscopic examination of animals, their liver, kidneys, spleen, lungs and tumor weights were measured. Peripheral blood was collected into EDTA-containing tubes for further analysis. Small tissue samples from the mentioned organs were fixed in $8 \%$ neutral buffered formalin, embedded in paraffin, sectioned at $5-6 \mathrm{mkm}$ thick and stained with haematoxylineosin using standard histopathological techniques. The sections were examined by light microscopy.

For electron microscopy studies the tumor samples were fixed for 1 hour in $1.6 \%$ glutaraldehyde solution prepared in $0.1 \mathrm{M}$ cacodylate buffer ( $\mathrm{pH}$ 7.3). To remove glutaraldehyde, the cells were washed in $0.1 \mathrm{M}$ cacodylate buffer for $16-18 \mathrm{~h}$. To achieve optimal isotonic quality of fixing and washing buffers, cacodylate buffer was supplemented with saccharose $(50 \mathrm{mg} / \mathrm{ml})$. Postfixation was done in $4 \% \mathrm{OsO}_{4}$ solution, with further dehydratation in alcohols and placement in the araldyte by standard method. Ultrathin slides were prepared with LKB-8800 ultratome (Sweden), were stained with uranyl acetate and plumbum citrate and then were examined using electron microscope JEM-100B (JEOL, Japan) at accelerating voltage of $80 \mathrm{kV}$.

\subsection{Thin-Layer Chromatography}

The qualitative and quantitative compositions of total lipids and phospholipids were determined by thin-layer chromatography method using plates "Sorbfil" PTSH-AF

Table 1. Description of studied groups of animals

\begin{tabular}{|c|c|c|c|c|}
\hline Groups of animals & Number of animals & Tested drugs & Code & Regime of application \\
\hline 1 & 10 & Control & $\mathrm{C}$ & $0.4 \mathrm{ml}$ of 199 medium \\
\hline 2 & 10 & Cisplatin «Ebewe» & $\operatorname{cis} \mathrm{P}$ & i.v. 4 times (once in 2 days); $1.2 \mathrm{mg} / \mathrm{kg}$ of weight \\
\hline 3 & 10 & $\begin{array}{l}\text { Cisplatin «Ebewe» }+ \\
\text { static magnetic field }\end{array}$ & $\operatorname{cis} \mathrm{P}+\mathrm{SMF}$ & $\begin{array}{l}\text { after every of } 4 \text { cisP i.v. injections static magnetic field } \\
\text { with induction of } 200-600 \mathrm{mT} \text { was applied for } 30 \mathrm{~min}\end{array}$ \\
\hline 4 & 10 & Nanocomposite & $\mathrm{NC}$ & $\begin{array}{l}\text { i.v. } 4 \text { times (once in } 2 \text { days); } 1.2 \mathrm{mg} / \mathrm{kg} \text { of weight of cisP } \\
\text { and } 1 \mathrm{mg} / \mathrm{kg} \text { of weight of for every injection; NC particle } \\
\text { size was } 30-40 \mathrm{~nm}\end{array}$ \\
\hline 5 & 10 & $\begin{array}{l}\text { Nanocomposite }+ \text { static } \\
\text { magnetic field }\end{array}$ & $\mathrm{NC}+\mathrm{SMF}$ & $\begin{array}{l}\text { after every of } 4 \mathrm{NC} \mathrm{i/v} \mathrm{injections} \mathrm{static} \mathrm{magnetic} \mathrm{field} \\
\text { with induction of } 200-600 \mathrm{mT} \text { was applied for } 30 \mathrm{~min}\end{array}$ \\
\hline
\end{tabular}


-A ("Imid Ltd", Krasnodar, Russia). To realize this purpose the lipids from Guerin carcinoma cells were extracted using a chloroform/methanol solvent mixture $(1: 1 ; \mathrm{v} / \mathrm{v})$. The thinlayer chromatography of total lipids was carried out only in one direction in the hexane/diethyl ether/glacial acetic acid solvent system $(85: 15: 1 ; \mathrm{v} / \mathrm{v})$ [16].

The thin-layer chromatography of phospholipids was carried out in two mutually perpendicular directions [17]. The first solvent system was chloroform/methanol/ benzene/ammonia $(65: 30: 10: 6, \mathrm{v} / \mathrm{v})$. The second system was chloroform/methanol/benzene/acetone/glacial acetic acid/ water $(70: 30: 10: 5: 4: 1, \mathrm{v} / \mathrm{v})$. After the evaporation of the solvent system the plates were treated with $10 \% \mathrm{H}_{2} \mathrm{SO}_{4}$ in methanol and heated for $5 \mathrm{~min}$ at $180^{\circ} \mathrm{C}$. All chromatograms were scanned and scans were imaged with the program Picture J. Lipid content was expressed in percents. Seven experiments with each cell line were performed in this study.

\subsection{Atomic Absorption Spectrophotometry}

Concentration of intracellular Fe was assessed by means of mineralization by the method of dry cineration. The concentration of iron was measured by atomic absorption spectrophotometry (C115M1 "Selmi", Ukraine) using calibrating curve for iron standards (Sigma, Germany) at the range of studied concentrations.

\subsection{Total Blood Count and Biochemical Analysis of Blood Serum}

After euthanasia of animals blood sample was carried out in EDTA tubes for total analysis of blood and biochemical analysis of blood serum. Total blood count was performed on haemanalyser "Particle Counter 210" (Erma Inc., Tokyo). Biochemical analysis of blood serum was performed on biochemical analyser, we determined the levels of urea, creatinine, total bilirubin, activities of alanine aminotransferase (ALT), aspartate aminotransferase (AST), alkaline phosphatase (ALP), and gammaglutamyltrans peptidase (GGT).

\subsection{Statistical Analysis}

All values were expressed as mean $\pm \mathrm{SD}$. Results were tested for significance with one-way analysis of variance (ANOVA). P-values $<0.05$ were considered statistically significant.

\section{Results and Discussion}

Study of sensitive to cisP Guerin carcinoma growth dynamics under impact of different courses of therapy showed, that combined application of $\mathrm{NC}$ and static magnetic field $(\mathrm{NC}+\mathrm{SMF})$ caused the best anti-tumor

\section{effect (Figure 1).}

According to the obtained data, cisP inhibited Guerin carcinoma growth by $26.4 \%$. Applying the combined effect of anticancer drug with local influence of SMF on the tumor resulted in enhancement of growth inhibition rate up to $38.4 \%$. NC exhibited the similar anti-tumor activity. But the most significant anti-tumor effect was observed when after intravenous $\mathrm{NC}$ injection the tumor was affected with SMF.

Thus, the comparative evaluation of anti-tumor activity of drugs used in animals with Guerin carcinoma showed that NC in combination with SMF exercises more prominent anti-tumor activity than cisP alone.

We performed light optical, morphological and electron-microscopic studies of the changes that occur in these tumors under the influence of NC and SMF in comparison with other factors effects.

While analyzing the obtained data, first of all, it should be noted that regardless of the therapeutic agent, in Guerin carcinoma we observed cytotoxic effects of the same profile type-deviation of cells adhesion and different manifestation degrees of dystrophy, necrobiotic changes development, cell death by means of necrosis or apoptosis, as well as signs of fibrous organization of damaged tumor tissue. However, the degree of these changes' manifestation depended on the type of applied factor.

Tumor cells sites with pronounced signs of cyto architectonic disturbances were the typical manifestation of changes that have taken place in tumors after cisP administration. These cells were characterized by polymorphism due to the large number of different by size and shape one-, dual- and multinucleated giant cells (Figure 2(b)). Their appearance is due to the fact that DNA is the target of cisP effect on tumor cells. As a result of structural and functional DNA abnormalities and

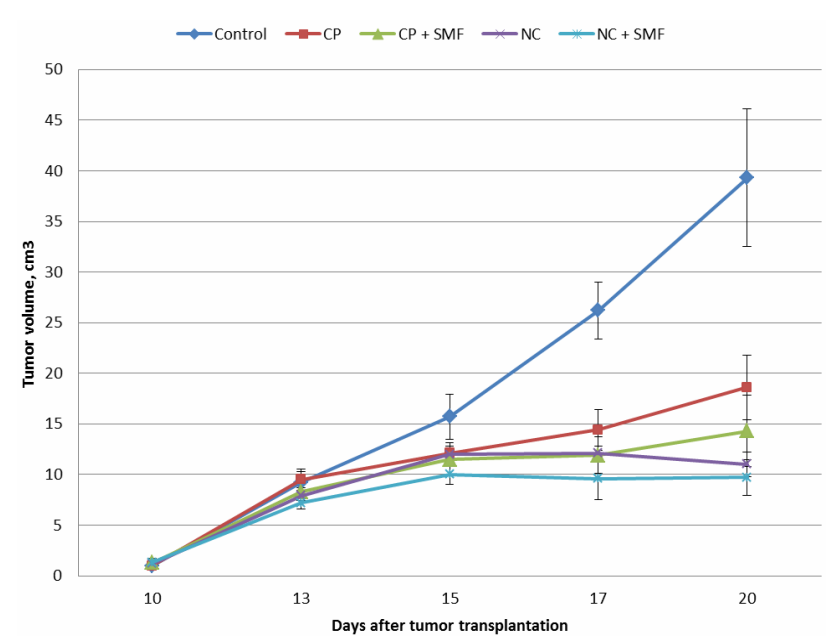

Figure 1. Guerin carcinoma growth dynamics under cisP and NC impact. 
associated changes in cell cycle and cell division the socalled "giants of drug pathomorphosis" appeared. In addition, we observed small foci of modified tumor cells, similar to this in control cells with signs of mild vacuolar-hydropic dystrophy, as well as areas of necrobiotic changes and necrosis.

Cisplatin combined with external magnetic field caused following changes in tumors, namely: more significant cells separation, degenerative changes worsening, particularly vacuolar-hydropic dystrophy, with formation of foci of balloon like cells and large areas with honeycomb like structure (Figures 2(c) and (d)). According to electron microscopy data, the tumor cells with altered cytoarchitecture often were located near vessels with signs of epithelial cells dystrophy and interruptions of endothelial pad integrity (Figure 2(e)), which contributed to vascular permeability changes and greater cisP inflow in tumor cells.

Manifestations of NC effects were more pronounced signs of cells' vacuolar-hydropic dystrophy. As a consequence, their cytoarchitecture in some areas of the tumor acquired forms of reticular structures that were formed by cytoplasmic membrane of "devastated" tumor cells that anastomosed with each other. At the ultrastructural level, the main sign of degenerative changes was marked disorganization of granular endoplasmic reticulum and mitochondria. Electron-dense granules of NPs composite were determined in cytoplasm in some cells. On the periphery and in the central sites of tumors we observed tumor cell death by means of necrosis, foci of apoptotic corpuscles, and the tendency to the replacement of destroyed tumor tissue by connective tissue. We consider that more pronounced and significant effects of NC, comparing with the action of other factors, are due to direct cisP effect on cells, on one hand, and on the other - to strengthening of its cytotoxic effect by magnetic fluid. According to literature data, the anti-tumor drugs, which are used in new transport nanoforms, acquire specific properties and are able to enter the cell freely, especially if they are nanoferromagnetics that possess high reactive properties and catalytic activity $[7,8]$.

The most prominent manifestations of pathomorphosis in tumor tissue were observed under combined action of $\mathrm{NC}$ and SMF. Besides foci of viable cells, the sites of tumor cells with varying degrees of degenerative changes and necrobiosis phenomena (Figure 2(f)), the extensive fields and foci of necrosis, and sites of dead cells caused by apoptosis were found (Figure 2(g)). In tumor cells of this group of animals compared to those that received only NC in electron microscopy studies we noticed significantly high NC accumulation both in form of granules diffusely distributed in cytoplasm and in form of aggregate combination in cytoplasm and nucleus (Figure 3). In parallel to destructive processes taking place under
NC influence and SMF impact on tumor, fibrotic organization of areas of dying tumor cells was observed (Figure 2(h)).

Comparative analysis of the results of using as antitumor drugs cisP; cisP in combination with tumor exposure to SMF; NC, and NC and SMF, showed that the most pronounced cytotoxic effect was achieved with

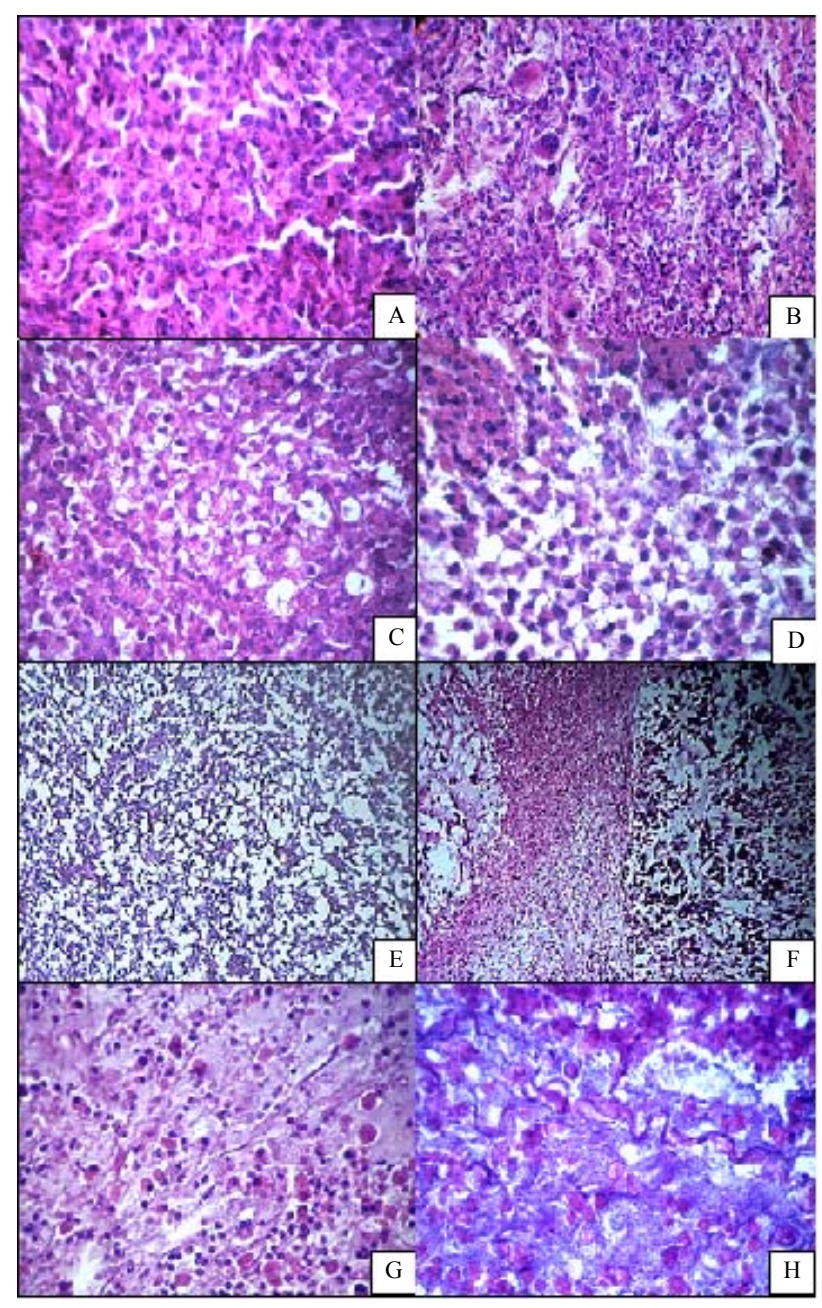

Figure 2. Changes in tumor cells cytoarchitectonics after impact of NC and cisP; (a) Guerin carcinoma tumor cells. Cells have solid growth. Hematoxylin-eosin. $\times 400$; (b) Big number of gigantic cells in Guerin carcinoma after cisP treatment. Hematoxylin-eosin. $\times 400$; (c), (d) Tumor cells with different stages of vacuole-hydrophic dystrophy after impact of cisP and SMF. Hematoxylin-eosin. $\times 400$; (e) Formation of net-like structures and vacuole-gidropic dystrophy in Guerin carcinoma cells after NC treatment. Hematoxylin-eosin. ×100; (f) Death of Guerin carcinoma cells: vacuole-hydrophic dystrophy (left), necrobiosis (right), cell detritus formation (center) after combined action of NC and SMF. Hematoxylin-eosin. $\times 100$; (g) Fibrosis organization of dying cells and formation of apoptotic bodies after impact of NC and SMF. Hematoxylin-eosin. $\times 400$; (h) Formation of connective tissue in the locus of dying cells after NC and SMF. Hematoxylin-eosin. $\times \mathbf{4 0 0}$. 


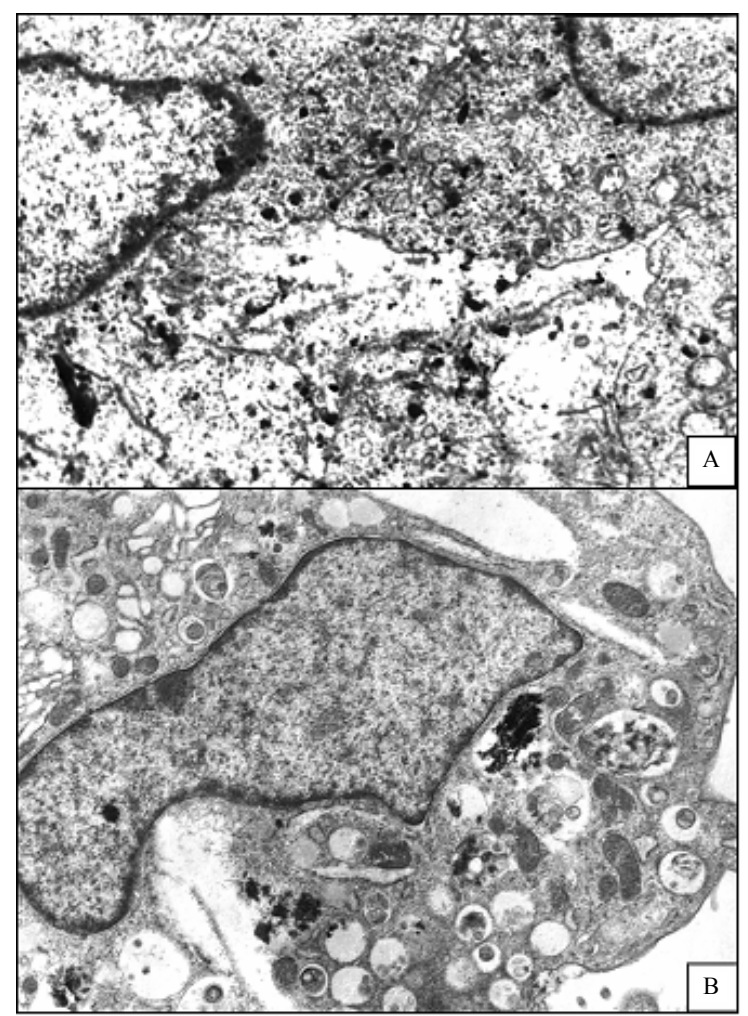

Figure 3. Localization of NC granules in tumor cells after impact of NC and SMF; (a) NC granules of high electron density show diffuse distribution in tumor cells cytoplasm. Electron microscopy, $\times 13,000$; (b) NC aggregates are visualized in tumor cells cytoplasm. Electron microscopy, $\times 15,000$.

nanosystem of targeted transport-intravenous NC injection in combination with an external magnetic radiation on tumor focus. Significant prevalence of morphological changes in the tumor tissue under the influence of the $\mathrm{NC}$ and SMF is the consequence of their cooperative action, mutually reinforced by the influence of each system component, particularly by directing actions of the magnetic field, so that in this group of animals the necrobiosis, necrosis and apoptosis phenomena were most prominent.

In addition to evaluating the peculiarities of changes in Guerin carcinoma caused by NC in combination with SMF compared with free cisP action we performed the investigations of cytotoxic effect of these factors on the cytoarchitecture of the vital organs of animals-lungs, liver, kidney and spleen. Most pronounced changes were detected in liver and kidney, mainly in kidney, when cisP, and directed transport system were used. In liver of rats, treated with cisP, comparing with control (Figure 4(a)), it was noticed the disturbances of organ girder structure, the dystrophy phenomenon, and in some animals-necrosis of hepatocytes surrounding expanded central vein, often filled with blood with signs of hemolysis and plas- molysis (Figure 4(b)). Changes in the liver of those animals subjected to the impact of $\mathrm{NC}$ in combination with tumor exposure to SMF were somewhat less pronounced. They consisted in disorganization of hepatocytes girder structure, Kupffer cells' hyperplasia, signs of vacuolar degeneration of hepatocytes and blood congestion in dilated vessels (Figure 4(c)).

In kidneys of animals, treated with cisP, in some cases we observed edema of convoluted tubules and glomeruli of cortical area, in other cases - cystiform extension of the proximal convoluted tubules, atrophy or hypertrophy of glomeruli, contraction of Shumlyanskii-Bowen capsule (Figure (4d)). Changes in kidneys of animals who received $\mathrm{NC}$ and magnetic radiation on the tumor, only edema of convoluted tubules with narrowing of their lumen, and dystrophic changes of these tubules epithelium were found (Figure 4(f)).

Changes in the spleen caused by cisP or by $\mathrm{NC}$ in combination with SMF, were unidirectional-expanding

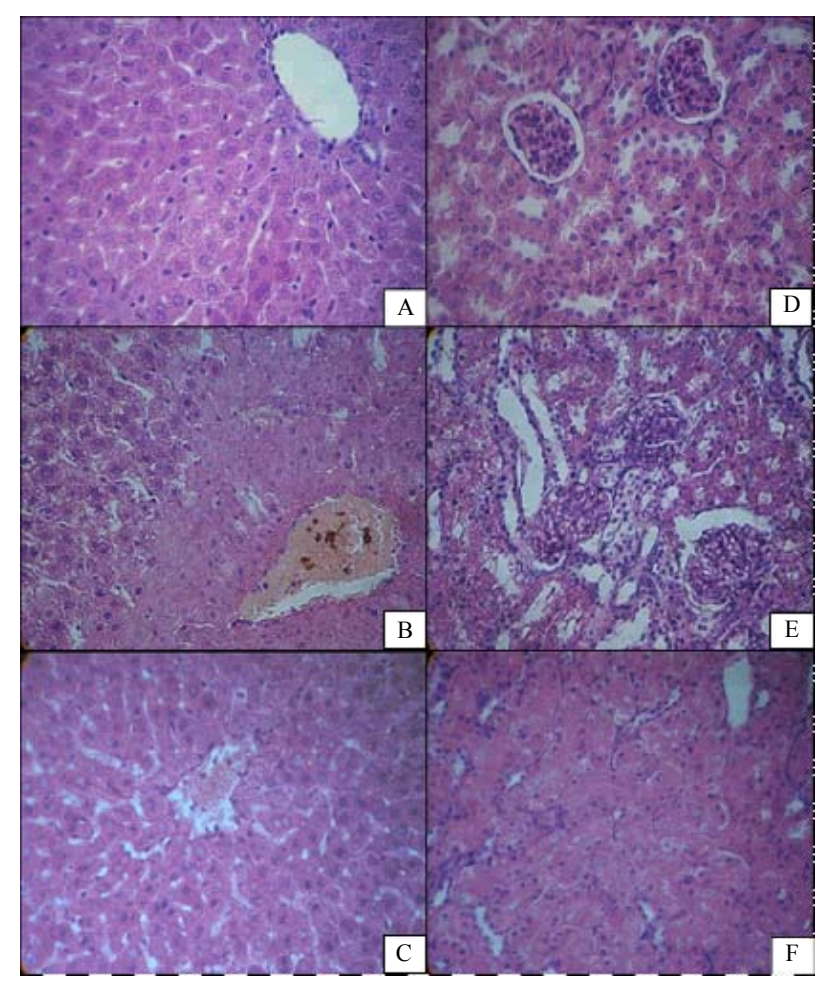

Figure 4. Changes in liver and kidneys after impact of NC and CP. (a) Liver (control). Hematoxylin-eosin. $\times 400$; (b) Liver structure is disrupted, hepatocyte necrobiosis around central vein after cisP treatment. Hematoxylin-eosin. $\times 400$; (c) Moderate disruption of liver structure vacuole dystrophy in hepatocytes after combined NC and SMF treatment. Hematoxylin-eosin. $\times 400$; (d) Kidney (Control). Hematoxylin-eosin. $\times 400$; (e) Cystic extension of renal tubules, edema and glomerular hypertrophy and reduction of Bowen capsule in renal tissue after cisP treatment. Hematoxylin-eosin. $\times 400$; (f) Eedema in renal tubules after NC and SMF. Hematoxylin-eosin. $\times 400$. 
the boundaries of white pulp by perifolicular hyperplasia of lymphocytes, significantly pronounced response of red pulp of megakaryocytes (Figures 5(b) and (c)) compared with control (Figure 5(a)). Thus, the changes that have occurred in the vital organs of animals with sensitive to cisP Guerin carcinoma under the influence of $\mathrm{NC}$ and SMF were slightly lower than under the action of free cisP. We consider that this is the consequence of the SMF directed income of the majority of NC directly into the tumor tissue.

Comparison analysis of $\mathrm{NC}$ accumulation in tumors of animals received only $\mathrm{NC}$ with the results of its accumulation after magnetic field local tumor exposure showed that the SMF results in greater NC inflow to the tumor (Table 2).

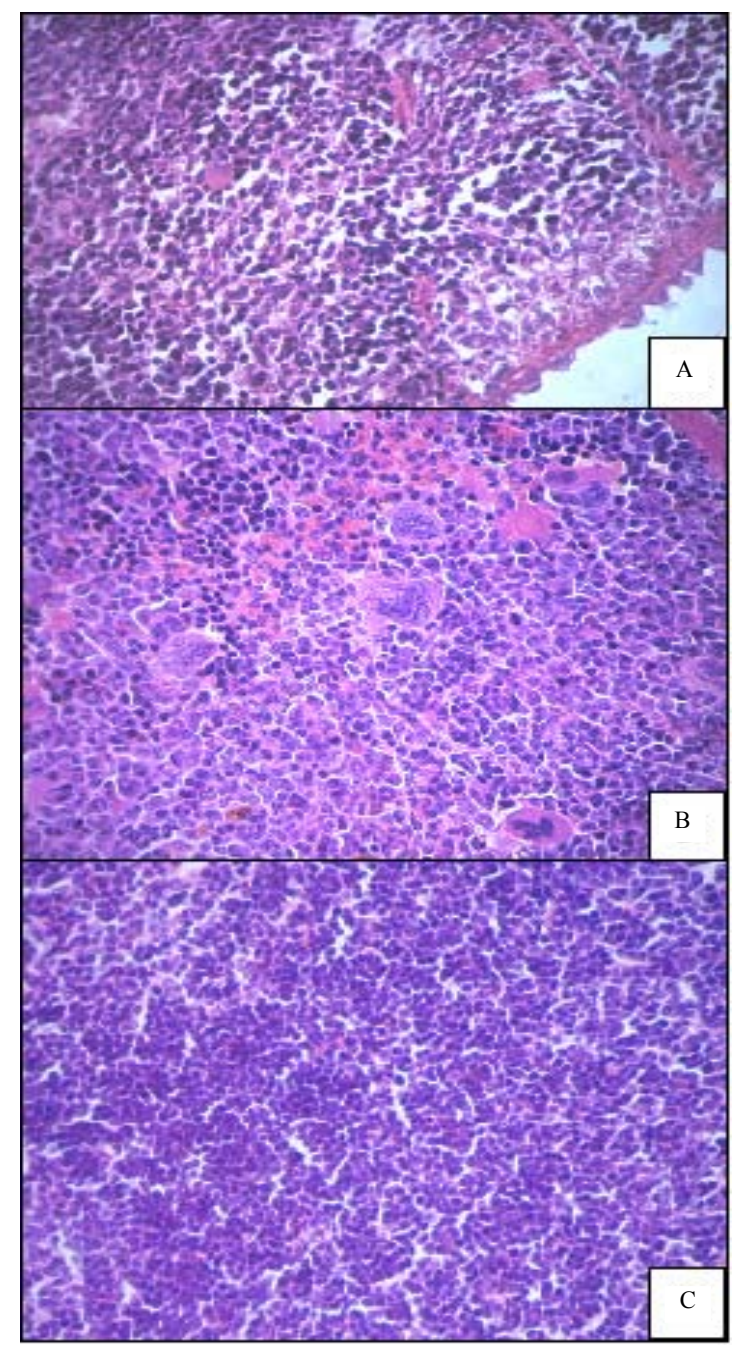

Figure 5. Changes in spleen after impact of NC and SMF. (a) Liver (control). Hematoxylin-eosin. $\times 400$; (b) Elevation of megakaryocyte number in red pulp after NC and SMF impact. Hematoxylin-eosin. $\times 400$; (c) Enlargement of white pulp zone due to perifollicular lymphocyte hyperplasia after NC and SMF impact. Hematoxylin-eosin. $\times 400$.
In the absence of the magnetic field influence tumor content of the $\mathrm{NC}$ was $37.5 \pm 2.3 \mathrm{Fe} \mathrm{mkg} / \mathrm{g}$ of tissue. Under the combined action of $\mathrm{NC}$ with local magnetic radiation on the tumor the $\mathrm{NC}$ level reached $79.1 \pm 3.1$ $\mathrm{Fe} \mathrm{mkg} / \mathrm{g}$ of tissue $(\mathrm{P}=0.02 ; \mathrm{n}=10$; Table 2$)$, i.e., it increased almost twice.

Because in the process of anticancer drugs inflow into cells an important role plays the ratio of lipids in cells themselves and in their membranes, we studied the qualitative and quantitative changes of total lipids and phospholipids composition in Guerin's carcinoma cells under the influence of $\mathrm{NC}$, as well as in the liver as it is the target organ for toxic effects in order to determine possible toxic effects of this factor. It is known that lipids are one of the components of cytoplasmic membrane, and some minor phospholipids play regulatory role in certain metabolic processes in cells [18]. Therefore, their contents changes' can affect cells functional activity. According to the results of our studies four times NC administration to an animal resulted in changes of both total lipids and phospholipids compositions in tumor tissue (Table 3). Special attention deserves cholesterol level reduction, because cholesterol is a component of membrane rafts, and its content decline leads to membrane fluidity increase and consequently to their permeability augmentation. Thus, under the influence of NC some changes in the lipid composition of tumor cells occur, which lead to modifications in cell membranes thereby improving the permeability and accumulation of anti-tumor agent in the tumor. Just that improves effectiveness of its action. At the same time, phospholipids composition in the liver of animals treated with $\mathrm{NC}$ did not change in fact (Table 4). It means that four times NC intravenous administration was low toxic for liver.

Furthermore, for investigation the side effects of NC we determined common and biochemical parameters of the peripheral blood (Tables 5 and $\mathbf{6}$ ). The administration of NC did not affect the blood common indexes, but increased serum creatinine level. The increase in creatinine was associated with the toxic effects of cisP as a part of the NC. But the magnitude of this biochemical index was significantly lower than that in tumor-bearing animals treated with cisP only.

Table 2. Quntitative evaluation by atom-adsorption spectrophotometry of iron content in Guerin carcinoma tissue after NC treatment

\begin{tabular}{cc}
\hline Groups & Fe concentration, mkg/g of tissue \\
\hline C & $33.6 \pm 3.0$ \\
$\mathrm{NC}$ & $37.5 \pm 3.4$ \\
$\mathrm{NC}+\mathrm{SMF}$ & $79.1 \pm 4.7^{*}$ \\
\hline
\end{tabular}

*Significantly $(\mathrm{P}<0.05)$ higher compared to control. 
Table 3. Lipid content of Guerin carcinoma cells (in \%) after SMF and NC impact.

\begin{tabular}{|c|c|c|c|c|}
\hline \multicolumn{5}{|c|}{ General lipids } \\
\hline & $\mathrm{C}$ & SMF & $\mathrm{NC}$ & $\mathrm{NC}+\mathrm{SMF}$ \\
\hline Phospholipids & $40.2 \pm 2,6$ & $44.6 \pm 2.9$ & $38.5 \pm 2.6$ & $12.2 \pm 1.3 \downarrow$ \\
\hline Monoglycerides & 0 & 0 & 0 & 0 \\
\hline Cholesterol & $27.3 \pm 1.9$ & $25.2 \pm 0.9$ & $18.0 \pm 1.6 \downarrow$ & $13.2 \pm 1.9 \downarrow$ \\
\hline Free fatty acids & 0 & 0 & 0 & 0 \\
\hline Diglycerides & $17.6 \pm 1.4$ & $14.5 \pm 2.3$ & $12.5 \pm 1.1 \downarrow$ & $11.5 \pm 0.5 \downarrow$ \\
\hline Triglycerides & $15.0 \pm 2.9$ & $15.6 \pm 2.5$ & $31.1 \pm 2.6 \uparrow$ & $63.2 \pm 1.8 \uparrow$ \\
\hline Cholesterol ethers & 0 & 0 & 0 & 0 \\
\hline \multicolumn{5}{|c|}{ Phospholipids } \\
\hline & $\mathrm{C}$ & SMF & $\mathrm{NC}$ & $\mathrm{NC}+\mathrm{SMF}$ \\
\hline Lysophosphatydylcholine & $5.1 \pm 0.3$ & $10.47 \pm 0.7 \uparrow$ & $6.3 \pm 1.1$ & $10.8 \pm 2.1 \uparrow$ \\
\hline Sphingomyeline & $7.0 \pm 0.7$ & $11.7 \pm 2.1 \uparrow$ & $7.6 \pm 1.5$ & $11.1 \pm 0.7 \uparrow$ \\
\hline Phosphatydylserine & $5.9 \pm 1.4$ & $10.1 \pm 1.6$ & $6.8 \pm 0.8$ & $8.4 \pm 0.9$ \\
\hline Phosphatydylinositol & $5.8 \pm 0.5$ & $11.9 \pm 0.7$ & $7.9 \pm 0.8$ & $7.7 \pm 1.1$ \\
\hline Phosphatydylcholine & $41.5 \pm 2.3$ & $29.1 \pm 5.0 \downarrow$ & $40.7 \pm 3.3$ & $30.6 \pm 1.4 \downarrow$ \\
\hline Phosphatydylethanolamine & $28.6 \pm 1.8$ & $16.4 \pm 2.2$ & $22.0 \pm 1.4$ & $21.9 \pm 2.0$ \\
\hline Diphosphatydylglycerol & $6.0 \pm 0.4$ & $10.3 \pm 2.3$ & $8.6 \pm 1.0$ & $9.5 \pm 0.6$ \\
\hline
\end{tabular}

$\uparrow$ : significantly $(\mathrm{P}<0.05)$ higher compared to control; $\downarrow$ : significantly $(\mathrm{P}<0.05)$ lower compared to control.

Table 4. Lipid content of hepatocytes of Guerin carcinoma-bearing rats (in \%) after SMF and NC impact.

\begin{tabular}{|c|c|c|c|c|}
\hline \multicolumn{5}{|c|}{ General lipids } \\
\hline & $\mathrm{C}$ & SMF & $\mathrm{NC}$ & $\mathrm{NC}+\mathrm{SMF}$ \\
\hline Phospholipids & $22.6 \pm 0.3$ & $21.3 \pm 1.2$ & $18.0 \pm 1.0 \downarrow$ & $17.0 \pm 1.9 \downarrow$ \\
\hline Monoglycerides & $7.7 \pm 1.5$ & $5.7 \pm 0.5$ & $3.4 \pm 0.9$ & $3.5 \pm 1.1$ \\
\hline Cholesterol & $23.0 \pm 2.1$ & $15.7 \pm 2.0$ & $18.2 \pm 1.6$ & $18.8 \pm 3.2$ \\
\hline Free fatty acids & 0 & 0 & 0 & 0 \\
\hline Diglycerides & $16.0 \pm 0.8$ & $21.7 \pm 3.5$ & $19.3 \pm 0.7 \uparrow$ & $17.5 \pm 1.5$ \\
\hline Triglycerides & $24.0 \pm 2.4$ & $35.6 \pm 6.5$ & $35.5 \pm 2.3 \uparrow$ & $37.6 \pm 5.4$ \\
\hline Cholesterol etheres & $6.8 \pm 0.5$ & $0 \downarrow$ & $5.7 \pm 0.9$ & $5.6 \pm 0.3$ \\
\hline \multicolumn{5}{|c|}{ Phospholipids } \\
\hline & $\mathrm{C}$ & SMF & $\mathrm{NC}$ & $\mathrm{NC}+\mathrm{SMF}$ \\
\hline Lysophosphatydylcholine & $4.5 \pm 0.1$ & $4.8 \pm 0.1$ & $5.2 \pm 1.1$ & $5.8 \pm 1.7$ \\
\hline Sphingomyeline & $6.8 \pm 0.5$ & $6.8 \pm 0.8$ & $8.5 \pm 1.6$ & $6.4 \pm 1.4$ \\
\hline Phosphatydylserine & $5.1 \pm 0.1$ & $5.4 \pm 0.9$ & $4.9 \pm 1.5$ & $6.8 \pm 1.4$ \\
\hline Phosphatydylinositol & $5.3 \pm 0.8$ & $4.9 \pm 0.6$ & $5.9 \pm 0.4$ & $7.2 \pm 1.1$ \\
\hline Phosphatydylcholine & $48.0 \pm 0.9$ & $45.7 \pm 2.1$ & $44.8 \pm 1.5$ & $43.3 \pm 3.2$ \\
\hline Phosphatydylethanolamine & $24.8 \pm 1.8$ & $26.9 \pm 0.5$ & $24.4 \pm 2.5$ & $23.4 \pm 2.9$ \\
\hline Diphosphatydylglycerol & $5.6 \pm 0.7$ & $5.4 \pm 1.1$ & $6.4 \pm 0.3$ & $6.6 \pm 0.6$ \\
\hline
\end{tabular}

$\uparrow$ : significantly $(\mathrm{P}<0.05)$ higher compared with control; $\downarrow$ : significantly $(\mathrm{P}<0.05)$ lower compared with control. 
Table 5. General indexes of blood of Guerin carcinoma-bearing rats after cisP, NC and SMF impact.

\begin{tabular}{cccccccc}
\hline \multirow{2}{*}{ Group } & \multicolumn{7}{c}{ Blood characteristics } \\
\cline { 2 - 8 } & $\begin{array}{c}\text { White blood cells, } \\
\times 10^{6} / \mathrm{ml}\end{array}$ & $\begin{array}{c}\text { Lymphocytes, } \\
\times 10^{6} / \mathrm{ml}\end{array}$ & $\begin{array}{c}\text { Monocytes, } \\
\times 10^{6} / \mathrm{ml}\end{array}$ & $\begin{array}{c}\text { Granulocytes, } \\
\times 10^{6} / \mathrm{ml}\end{array}$ & $\begin{array}{c}\text { Red blood cells, } \\
\times 10^{12} / \mathrm{ml}\end{array}$ & $\begin{array}{c}\mathrm{Hb}, \mathrm{g} / \mathrm{dl} \\
\times 1.3\end{array}$ & $\begin{array}{c}\text { Platelets, } \\
\times 10^{6} / \mathrm{ml}\end{array}$ \\
\hline $\mathrm{C}$ & $12.6 \pm 2.3$ & $6.2 \pm 1.3$ & $2.4 \pm 0.3$ & $4.0 \pm 1.2$ & $5.3 \pm 1.0$ & $8.3 \pm 1.2$ & $356.0 \pm 80.0$ \\
cisP & $15.7 \pm 2.0$ & $7.0 \pm 1.4$ & $4.0 \pm 0.8$ & $5.0 \pm 1.1$ & $4.7 \pm 1.0$ & $8.6 \pm 1.2$ & $335.0 \pm 76.0$ \\
$\mathrm{cisP}+\mathrm{SMF}$ & $13.4 \pm 1.4$ & $5.6 \pm 0.6$ & $2.1 \pm 0.4$ & $5.0 \pm 0.7$ & $5.5 \pm 0.6$ & $9.0 \pm 0.7$ & $371.8 \pm 82.9$ \\
$\mathrm{NC}$ & $14.5 \pm 2.1$ & $7.8 \pm 1.1$ & $2.6 \pm 0.5$ & $6.0 \pm 1.0$ & $5.3 \pm 0.6$ & $8.9 \pm 0.7$ & $327.4 \pm 54.5$ \\
$\mathrm{NC}+\mathrm{SMF}$ & $15.0 \pm 2.4$ & $7.7 \pm 1.2$ & $2.1 \pm 0.5$ & $5.4 \pm 1.1$ & $5.4 \pm 0.7$ & $9.0 \pm 0.6$ & $300.0 \pm 40.0$ \\
\hline
\end{tabular}

Table 6. Biochemical indexes of serum of Guerin carcinoma-bearing rats after CP, NC and SMF impact.

\begin{tabular}{|c|c|c|c|c|c|c|c|}
\hline \multirow{2}{*}{ Group } & \multicolumn{7}{|c|}{ Serum characteristics } \\
\hline & $\begin{array}{c}\text { Carbamide, } \\
\mathrm{mM}\end{array}$ & Creatinine $\mathrm{mkM}$ & $\begin{array}{c}\text { AST activity, } \\
\mathrm{U} / 1\end{array}$ & $\begin{array}{c}\text { ALT activity, } \\
\text { U/1 }\end{array}$ & $\begin{array}{l}\text { ALP activity, } \\
\text { U/1 }\end{array}$ & $\begin{array}{c}\text { GGT activity, } \\
\text { U/1 }\end{array}$ & $\begin{array}{c}\text { General bilirubin } \\
\text { level, mkM }\end{array}$ \\
\hline $\mathrm{C}$ & $16.2 \pm 4.0$ & $43.0 \pm 2.1$ & $494.0 \pm 80.0$ & $50.6 \pm 2.2$ & $302.6 \pm 47.1$ & $7.4 \pm 1.0$ & $9.6 \pm 1.0$ \\
\hline $\operatorname{cis} \mathrm{P}$ & $19.0 \pm 3.0$ & $73.0 \pm 9.0 *$ & $500.0 \pm 62.0$ & $54.2 \pm 5.0$ & $298.6 \pm 37.4$ & $9.0 \pm 1.1$ & $10.3 \pm 1.3$ \\
\hline $\operatorname{cisP}+\mathrm{SMF}$ & $12.3 \pm 3.1$ & $59.0 \pm 4.0^{*}$ & $350.0 \pm 60.0$ & $45.2 \pm 4.6$ & $264.0 \pm 40.1$ & $6.7 \pm 0.4$ & $9.6 \pm 0.6$ \\
\hline $\mathrm{NC}$ & $16.0 \pm 3.0$ & $62.0 \pm 5.5^{*}$ & $465.0 \pm 36.0$ & $45.8 \pm 2.8$ & $263.8 \pm 35.8$ & $7.0 \pm 1.0$ & $11.0 \pm 1.3$ \\
\hline $\mathrm{NC}+\mathrm{SMF}$ & $20.6 \pm 3.2$ & $64.8 \pm 5.0^{*}$ & $400.0 \pm 60.0$ & $50.4 \pm 5.1$ & $320.5 \pm 40.0$ & $7.6 \pm 0.7$ & $10.2 \pm 1.1$ \\
\hline
\end{tabular}

*Significantly $(\mathrm{P}<0.05)$ higher compared with control.

\section{Conclusions}

1) According to the assessment of anti-tumor activity and the results of morphological studies of application of nanocomposite with magnetic fluid (as one of its components) used as vector for delivery of cisplatin to tumors, enhances its anti-tumor effect comparing with the cisplatin monotherapy.

2) The usage of directed transport system (combined effects of nanocomposite with local influence on the tumor, caused by static magnetic field) significantly increases the biological effects in tumor tissue; and toxicity towards vital organs are more tolerant than the effect of cisplatin.

3) Lack of significant damaging effect of nanocomposite on total and biochemical blood indexes, lipid composition of hepatocytes indicates its low toxicity and suggests the possibility of its use as a vector in nanosystems for anti-tumor drugs delivery.

\section{Acknowledgements}

The authors would like to thank the researches of the Department of Mechanisms of Anti-tumor Therapy of RE Kavetsky Institute of Experimental Pathology, Oncology and Radiobiology of NAS of Ukraine for assistance in the performance of experiments.

\section{Funding}

The study was funded by the National Academy of Sci- ences of Ukraine.

\section{REFERENCES}

[1] S. K. Sahoo, S. Parveen and J. J. Panda, "The Present and Future of Nanotechnology in Human Health Care," Nanomedicine, Vol. 3, No. 1, 2007, pp. 20-31. doi:10.1016/j.nano.2006.11.008

[2] X. Dong and R. J. Mumper, "Nanomedicinal Strategies to Treat Multidrug-Resistant Tumors: Current Progress," Nanomedicine, Vol. 5, No. 4, 2010, pp. 597-615.

[3] X. Chi, D. Huang D, Z. Zhao, Z. Zhou, Z. Yin and J. Gao, "Nanoprobes for in Vitro Diagnostics of Cancer and Infectious Diseases," Nanomaterials, Vol. 33, No. 1, 2012, pp.189-206.

[4] J. Ferlay, H. R. Shin, F. Bray, D. Forman, C. Mathers, and D. M. Parkin, "Estimates of Worldwide Burden of Cancer in 2008: GLOBOCAN 2008," International Journal of Cancer, Vol. 127, No. 12, 2010, pp. 2893-2917. doi:10.1002/ijc. 25516

[5] M. Chadambram, R. Manavalan and K. Kathiresan, "Nanotherapeutics to Overcome Conventional Cancer Chemotherapy Limitations," Journal of Pharmacy and Pharmaceutical Sciences, Vol. 14, No.1, 2011, pp. 67-77.

[6] O. P. Singh and R. M. Nehru, "Nanotechnology and Cancer Treatment," Asian Journal of Experimental Sciences, Vol. 22, No. 2, 2008, p. 6.

[7] R. Sinha, G. J. Kim, S. Nie and D. M. Shin, "Nanotechnology in Cancer Therapeutics: Bioconjugated Nanoparticles for Drug Delivery," Molecular Cancer Therapeutics, Vol. 5, No. 8, 2006, pp. 1909-1917. doi:10.1158/1535-7163.MCT-06-0141 
[8] B. Haley and E. Frenkel, "Nanoparticles for Drug Delivery in Cancer Treatment," Urologic Oncology, Vol. 26, No. 1, 2008, pp. 57-64. doi:10.1016/j.urolonc.2007.03.015

[9] V. F. Chekhun, "Role of Innovative Technologies in Solving of Oncological Problems," Visnyk NAS Ukraine, No. 9, 2008, pp. 38-42.

[10] A. P. Naga and A. Siddiqui, "Nanomedical Platform for Drug Delivery," Journal of Nanomedicine Nanotechnology, Vol. 2, 2011, p. 122.

[11] E. Gullotti and Y. Yeo, "Extracellularly Activated Nanocarriers: A New Paradigm of Tumor Targeted Drug Delivery," Molecular Pharmaceutics, Vol. 6, No. 4, 2009, pp. 1041-1051. doi: 10.1021/mp900090

[12] H. S. Choi and J. V. Frangioni, "Nanoparticles for Biomedical Imaging: Fundamentals of Clinical Translation," Molecular Imaging, Vol. 9, No. 6, 2010, pp. 291-310.

[13] B. Szalay, E. Tatrai, G. Nyiro, V. Tunde and G. Dura, "Potential Toxic Effects of Iron Oxide Nanoparticles in in Vivo and in Vitro Experiments," Journal of Applied Toxi- cology, Vol. 32, No. 6, 2012, pp. 446-453. doi: $10.1002 /$ jat. 1779

[14] UA Patent 99211, P. P. Horbyk, "Nanocapsule with Nanorobot Functions," 2012.

[15] N. Y. Lukianova, N. V. Rusetskaya, L. A. Naleskina and V. F. Chekhun, "Some Mechanisms of Nanocomposit Action on Sensitive and Resistant MCF-7 Cells," Materials of 7th CIS Oncologists' and Radiologisits' Meeting, Kazakhstan, 2012, p. 499.

[16] M. Kates, "Techniques of Lipidology. Isolation, Analysis and Identification of Lipids," 1975.

[17] V. E. Vaskovsky and T. A. Terekhova, "HPTLC of Phospholipid Mixtures Containing Phosphatidylglycerol," Journal of High Resolution Chromatography \& Chromatography Communications, Vol. 2, No. 2, 1979, pp. 671-672. doi: $10.1002 / \mathrm{jhrc} .1240021107$

[18] N. Todor, N. Yu. Lukianova and V. F. Chekhun, "The Lipid Content of Cisplatin- and Doxorubicin-Resistant MCF-7 Human Breast Cancer Cells," Experimental Oncology, Vol. 34, No. 2, 2012, pp. 97-100. 